\title{
Importance of eculizumab treatment in recurrence of atypical hemolytic uremic syndrome during the SARS-CoV-2 pandemic
}

\author{
Erhan $\operatorname{Tatar}^{1}$ (D) Zuleyha Can Erdi ${ }^{2} \cdot$ Oyku Ozgur $^{2} \cdot$ Anıl Tasdemir $^{2} \cdot$ Bengu Tatar $^{3}$
}

Received: 25 March 2021 / Accepted: 8 May 2021 / Published online: 18 May 2021

(c) The Author(s), under exclusive licence to Springer Nature B.V. 2021

\section{Editor,}

The pandemic of Coronavirus Disease 19 (COVID-19) continues as an important public health problem, nowadays [1]. This pandemic has affected many such chronic patients who were unable to receive their regular therapies. There is not enough information about how atypical hemolytic uremic syndrome (aHUS) cases affect the pandemic. We present a case of recurrent aHUS accompanied by severe kidney disease during the SARS-CoV-2 (Severe Acute Respiratory Syndrome causing Coronavirus) pandemic. This case also recovered exceptionally from COVID-19 pneumonia and was in remission again with eculizumab treatment in spite of serum creatinine $6.9 \mathrm{mg} / \mathrm{dL}$.

A 29-year-old female patient was being followed up in remission due to aHUS accompanying posterior reversible encephalopathy syndrome (PRES) [2]. Genetic analysis of complement protein genes was mutated at on the complement factor $\mathrm{H}$ (CFH -p.Glu936Asp, p.Arg1192Ile) antigen and CFHR5 genes (p.Arg356His) with associated aHUS. Her past medical history had 4-month hemodialysis treatment due to aHUS 4 years ago. She was in remission for 52 months with eculizumab treatment of $900 \mathrm{mg}$ every 15 days. She admitted to another hospital with fever and cough complaints. At admission, her body temperature was $38.7{ }^{\circ} \mathrm{C}$, oxygen saturation was $90 \%$. Chest tomography demonstrated bilateral widespread ground glass opacities.

Erhan Tatar

etatar@hotmail.com

1 Division of Nephrology, Izmir Bozyaka Education and Research Hospital, University of Health Sciences, 9035170, Karabaglar, Izmir, Turkey

2 Department of Internal Medicine, Izmir Bozyaka Education and Research Hospital, University of Health Sciences, Izmir, Turkey

3 Department of Infectious Diseases and Clinical Microbiology, Izmir Tepecik Training and Research Hospital, University of Health Sciences, Izmir, Turkey
The inflammatory involvement rate in lung parenchyma was $25 \%$. SARS-CoV-2 test was positive by nucleic acidbased polymerase chain reaction in throat swabs. She was diagnosed with COVID-19 pneumonia. At baseline, serum urea: $95 \mathrm{mg} / \mathrm{dL}$, serum creatinine: $3.6 \mathrm{mg} / \mathrm{dL}$, total leukocyte $3.8 \times 10^{3} / \mu \mathrm{L}$, lymphocyte $1.4 \times 10^{3} / \mu \mathrm{L}$, hemoglobin 11.7 g/L, thrombocyte: $218 \times 10^{3} / \mu \mathrm{L}, \mathrm{LDH}: 271 \mathrm{U} / \mathrm{L}, \mathrm{CRP}: 24.8$ $\mathrm{mg} / \mathrm{L}$. Hydroxychloroquine $800 \mathrm{mg} /$ day, favipiravir $2 \times 1600$ $\mathrm{mg}$ (first day), $2 \times 600 \mathrm{mg}$ (4 days) and moxifloxacin 400 $\mathrm{mg} /$ day (7 days) was given. She remained stable in terms of clinical and laboratory values during hospitalization (7 days). She was discharged after clinical improvement. It was learned that she did not come to the hospital for eculizumab treatment during COVID-19 pandemic and has not received treatment by herself for 45 days. Serum urea: $206 \mathrm{mg} / \mathrm{dL}$, creatinine: $6.90 \mathrm{mg} / \mathrm{dL}$, hemoglobin: $10.1 \mathrm{~g} / \mathrm{L}$, thrombocyte: $72 \times 10^{3} / \mu \mathrm{L}, \mathrm{LDH}: 343 \mathrm{U} / \mathrm{L}$. Thrombocyte values decreased to $50 \times 10^{3} / \mu \mathrm{L}$. Single dose $(1200 \mathrm{mg})$ eculizumab, and $100 \mathrm{mg}$ methylprednisolone (5 days) was given. The maintenance eculizumab treatment was continued every 15 days. First month of treatment, serum creatinine: 3.73 $\mathrm{mg} / \mathrm{dL}$, hemoglobin: $11.3 \mathrm{~g} / \mathrm{dL}$, thrombocyte: $193 \times 10^{3} / \mu \mathrm{L}$, LDH: 242 U/L. At the end of 6 months, control values were determined as serum creatinine: $3.6 \mathrm{mg} / \mathrm{dL}$, hemoglobin: $11.2 \mathrm{~g} / \mathrm{L}$, thrombocyte: $148 \times 10^{3} / \mu \mathrm{L}$. The laboratory tests are shown in Fig. 1. Currently, the patient is in remission, and during the follow up period treatment continues with eculizumab (1200 mg/15 days).

Although the case admitted with serum creatinine $6.9 \mathrm{mg} /$ $\mathrm{dL}$ during the SARS-CoV-2 pandemic, it was interesting that this case achieved seamlessly both renal and hematological remission with eculizumab treatment.

The COVID-19 pandemic may occur in different effects on cases with aHUS. First, recurrence of aHUS due to viral and bacterial infections is known. However, COVID-19 related aHUS relapse is extremely rare in the literature. In a case report by Ville $S$ et al. [3], the case with aHUS relapsed with the COVID-19 infection. This case was in remission 
Fig. 1 Serum creatinine, LDH and thrombocyte levels during follow-up

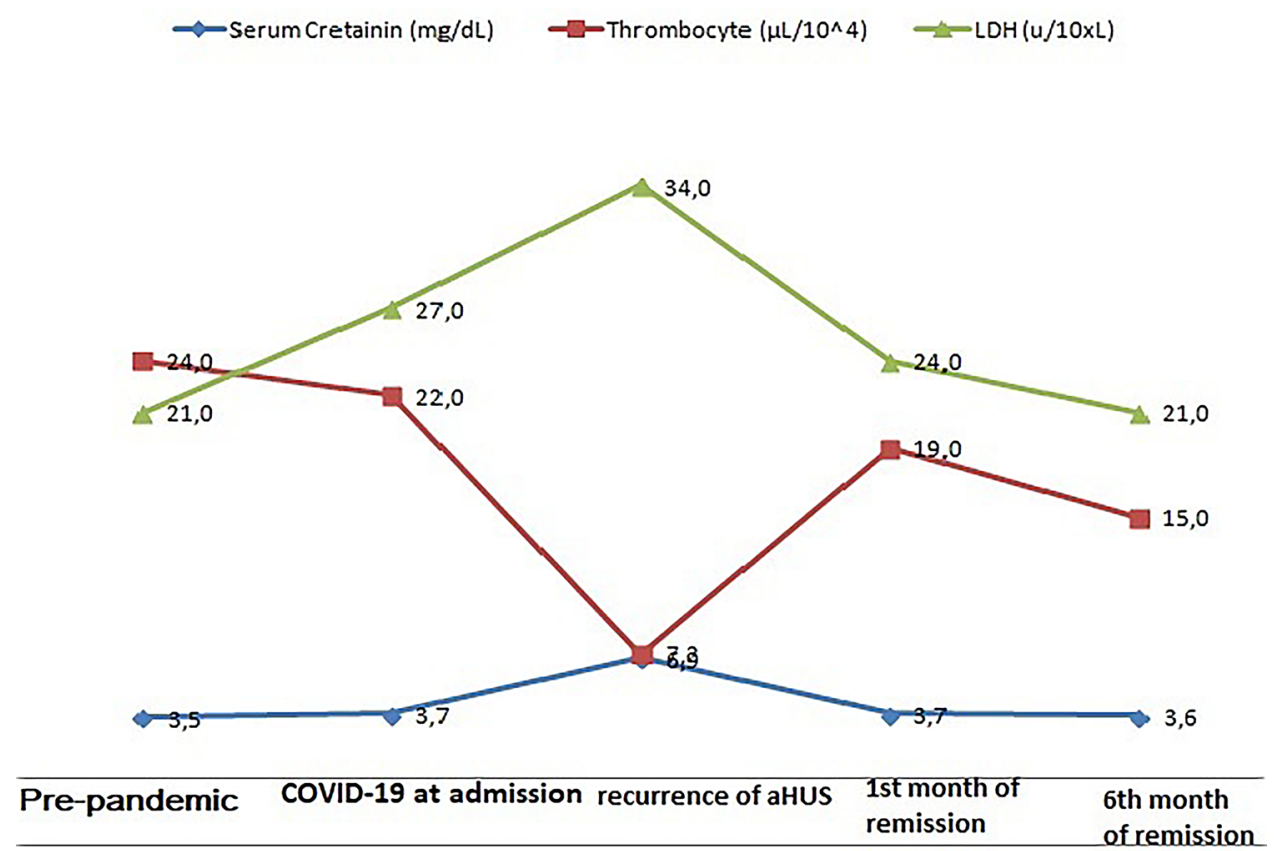

with eculizumab treatment. Second, during the pandemic process, disruptions of the eculizumab treatment may cause relapse of aHUS. The patient's fear of hospitalization due to the pandemic may be responsible for this situation. At the same time, the treatment may be disrupted due to lack of drug or hospital occupancy. Our patient did not apply to the hospital due to fear of infected by COVID-19 virus. Third, autopsy studies showed that it is the fatal course of COVID-19 due to microtromboembolisms by activating the complement cascade. Whether eculizumab will positively affect COVID-19 treatment is not yet known [4]. Trimarchi $\mathrm{H}$ et al. [5] reported a kidney transplant patient with aHUS who has severe COVID-19 pneumonia and an increase in severe endothelial damage markers were detected despite eculizumab treatment. The authors emphasized that eculizumab treatment could not prevent the development of severe pneumonia and endothelial damage during COVID19 disease in this case report [5].

As a result, the COVID-19 pandemic may negatively affects aHUS cases. In the presence of aHUS relapse, eculizumab is an effective treatment option regardless of the stage of kidney disease during the SARS-CoV-2 pandemic.

Funding This study was not funded by any financial support.
Informed consent The patient gave consent to the use of all data of her disease to be used for scientific purposes.

\section{References}

1. Ozturk S, Turgutalp K, Arici M et al (2020) Mortality analysis of COVID-19 infection in chronic kidney disease, haemodialysis and renal transplant patients compared with patients without kidney disease: a nationwide analysis from Turkey. Nephrol Dial Transplant 35(12):2083-2095

2. Medeni SS, Namdaroglu S, Cetintepe T, Ozlu C, Tasli F, Adibelli $\mathrm{ZH}$, Bilgir O, Tatar E (2018) An adult case of atypical hemolytic uremic syndrome presented with posterior reversible encephalopathy syndrome: Successful response to late-onset eculizumab treatment. Hematol Rep 10(3):7553

3. Ville S, Le Bot S, Chapelet-Debout A, Blancho G, FremeauxBacchi V, Deltombe C, Fakhouri F (2021) A typical HUS relapse triggered by COVID-19. Kidney Int 99(1):267-268

4. Conway EM, Pryzdial ELG (2020) Is the COVID-19 thrombotic catastrophe complement-connected? J Thromb Haemost 8(11):2812-2822. https://doi.org/10.1111/jth.15050 (Epub 2020 Sep 18.PMID: 32762081)

5. Trimarchi H, Gianserra R, Lampo M, Monkowski M, Eculizumab LJ (2020) SARS-CoV-2 and atypical hemolytic uremic syndrome. Clin Kidney J. 13(5):739-741. https://doi.org/10.1093/ckj/sfaa1 66 (eCollection 2020 Oct.PMID: 33117528)

Publisher's Note Springer Nature remains neutral with regard to jurisdictional claims in published maps and institutional affiliations.

\section{Declarations}

Conflict of interest No conflict of interest was declared. 